ORIGINAL ARTICLE

\title{
Exposure of pregnant women to tap water related activities
}

\author{
S Kaur, M J Nieuwenhuiijsen, H Ferrier, P Steer
}

Occup Environ Med 2004;61:454-460. doi: 10.1136/oem.2003.007351

See end of article for authors' affiliations .....................

Correspondence to: DrM J Nieuwenhuijsen, Department of Environmental Science \& Technology, Imperial College London, Royal School of Mines, South Kensington, Prince Consort Road, London SW7 2AZ, UK; m.nieuwenhuiisen@ imperial.ac.uk

Accepted 28 November 2003

\begin{abstract}
Background: Evidence for an association between exposure of pregnant women to chlorination disinfection by-products and adverse birth outcomes is inconsistent and inconclusive.

Aims: To evaluate the use of a questionnaire in a population of pregnant women to assess their exposure to water, examine the validity of the questionnaire by a seven day diary, and to obtain a better understanding of the exposure of pregnant women to water in Central London.

Methods: A total of 147 pregnant women were asked to complete a questionnaire. Information was requested on their exposure to water from cooking and washing up, showering and bathing, food and drink, and swimming. Demographic and socioeconomic information were also recorded. For validation purposes, women were asked to complete a seven day diary at home.

Results: The average exposure duration was $338.5 \mathrm{~min} /$ week for cooking and washing up, $172.2 \mathrm{~min} /$ week for bathing and showering, and $67.9 \mathrm{~min} / \mathrm{month}$ for swimming. The total fluid intake was $18.9 \mathrm{l} /$ week of which, on average, $18 \%$ was cold tap water; $30 \%$ of this tap water was consumed outside the home. The correlation between questionnaire and diary data was generally good to very good, although women tended to overestimate their exposure in the questionnaire compared to the diary.

Conclusions: Information was obtained on the daily exposure of pregnant women in Central London to chlorinated water at home, work, and elsewhere. The questionnaire was found to be a valid method to assess the exposure of pregnant women to water and the response rate was higher than for diaries.
\end{abstract}

$\mathrm{T}$ he disinfection of public water supplies by chlorination is common throughout the world today. It has remained a popular disinfectant choice, despite alternative disinfectants being available. With the discovery of disinfection byproducts (DBPs), a spectrum of halogenated compounds formed by reactions between naturally occurring organic matter in the water and the added chlorine, concerns have arisen concerning their impact on human health. The benefits of preventing many serious diseases continue to largely outweigh the potential risks, but further research is needed to quantify both risks and benefits.

Toxicological and epidemiological studies concerning DBPs have focused on potential associations between exposure to chlorination DBPs and human cancers. ${ }^{1-3}$ Recently, increasing attention has been given to the association between chlorination DBPs and adverse birth outcomes, ${ }^{45}$ particularly low birth weight, stillbirth, miscarriages, and congenital malformations. ${ }^{4-9} 15-17$

At present the evidence for an association between exposure of pregnant women to chlorination DBPs and adverse birth outcomes is generally inconsistent and inconclusive. ${ }^{45}$ There has been widespread recognition that the exposure assessment is the major point of weakness when studying such an association. ${ }^{10-13}$ The body of evidence showing associations between DBPs and reproductive effects in humans and animals continues to grow and, with new data, the evidence is becoming more consistent. Improved exposure assessments will strengthen future studies.

Exposure to DBPs, such as trihalomethanes (THMs), may occur through ingestion, inhalation, or dermal absorption during activities such as cooking and washing up, showering and bathing, fluid intake, and swimming. For other DBPs, such as haloacetic acids, ingestion is the main exposure route. ${ }^{10}$ The approach employed in studies to assess the exposure of pregnant women to chlorination DBPs has been mainly based on the water source or treatment and the concentration of total THMs in the municipal water source of the subject. ${ }^{510}$ This ignores the individual variability in the fluid intake, and showering, bathing, and swimming patterns of pregnant women, which may be important determinants for exposure to chlorination DBPs. ${ }^{10}$ This could produce exposure misclassification and hence attenuation in risk estimates and/or loss of statistical power. ${ }^{10}{ }^{14}$

Only a few epidemiological studies have taken into account ingestion, showering, and swimming as pathways of exposure ${ }^{6}{ }^{15-17}$ Recent studies have started to address this problem by performing more detailed assessments of exposure and studying the validity and reliability of questionnaires. ${ }^{14} 1819$ However, most of the work concerning the exposure of pregnant women to chlorination DBPs has been performed outside the UK, and international differences in personal behaviour may result in different exposure profiles.

This study aims to determine the cooking and washing up, showering and bathing, fluid intake, and swimming patterns of pregnant women in Central London and to evaluate the validity of the questionnaire with a seven day diary.

\section{METHODS}

\section{Study participants}

One hundred and eighty women were asked to participate in the study. They were mainly in their first trimester of pregnancy and attending their first registration appointment between 20 May and 26 July 2002 at the Chelsea \& Westminster Hospital antenatal clinic in Central London. All pregnant women lived in London and their recruitment was not restricted by any factors such as age, parity, socioeconomic status, or past pregnancy history. Participation was on a voluntary basis and the women received no payment for taking part in the study.

Pregnant women consenting to participate were asked to complete a questionnaire at the clinic. They were also given a seven day diary to complete at home and return in a provided stamped addressed envelope. Approval was obtained from

Abbreviations: DBPs, disinfection by-products; THM, trihalomethane 
Main messages

- There is considerable variation in the exposure to water among pregnant women.

- $22.8 \%$ of total fluid ingested was cold tap water; $69.8 \%$ of this was ingested at home. $37.0 \%$ of the overall fluid ingestion occurred outside the home environment.

- Collected results, validation analysis, and calculated correlations revealed the questionnaire to be a valid method for estimating exposure to water.

the Riverside Ethics Committee to recruit participants for this study.

\section{Data collection \\ Questionnaire}

Study participants were asked to complete a three page questionnaire. The questionnaire was designed to determine levels of use and consumption of water in a normal day. The respondents estimated the average time spent boiling water, washing-up by hand, using a dishwasher, bathing, and showering. They also estimated the time they spent in the bathroom following bathing or showering and the frequency and duration of swimming activity, either weekly or monthly. The study participants were asked to record their fluid intake habits at home, work/college, and elsewhere. Fluids were categorised as cold tap water, bottled water, tea, coffee, hot chocolate, plain milk, squash (fruit drink made with water), soft drinks, beer, wine, and spirits. The respondents were asked to express their daily or weekly intake of each item as a number of glasses $(200 \mathrm{ml})$, mugs $(200 \mathrm{ml})$, cans $(330 \mathrm{ml})$, or in precise liquid units if known. Women were also asked to report on the daily or weekly consumption of soup, expressed in mugs $(200 \mathrm{ml})$, bowls $(400 \mathrm{ml})$, or in known liquid units.

Demographic information, which might include modifying factors for water use, was recorded. This included questions on location of residence, maternal age, parity, level of education, work status, smoking habits, household income, and ethnic background.

\section{Seven day diary}

The seven day diary was used as a gold standard method of data collection and to validate the questionnaire. It consisted of seven identical pages, with each page recording the same information as the questionnaire (information regarding cooking and washing up, showering/bathing, food and drink, and swimming), but excluding demographic information. The women were expected to complete the diary for seven consecutive days.

Further details about the contents of both the questionnaire and the seven day diary are available in Kaur. ${ }^{20}$

\section{Statistical analysis}

For ease of handling the large data set, the fluid intake data collected for work/college and elsewhere were combined, giving data for fluid intake at home and elsewhere overall. The data were analysed with the Statistical Package for the Social Sciences, version 10.0 for Windows (SPSS Inc., 198999). Basic statistics were calculated to estimate the average fluid intake (total and separate categories), showering, bathing, and swimming duration per week for the questionnaire and seven day diary. The data collected from the questionnaires and the seven day diaries were compared to examine the validity of the questionnaire. Correlation between the results of the two methods was assessed by estimating Spearman's correlation coefficients. To estimate

\section{Policy implications}

- It is necessary to consider individual variability of exposure to chlorinated water.

- There are a number pathways and routes of exposure for by-products such as trihalomethanes among pregnant women, all of which must be considered.

- Further work should be performed to assess the contribution and importance of each exposure route.

the bias for each woman in the sample, the mean difference between the results of the questionnaire and the diary was calculated for each water use variable. These data were then used to calculate the mean difference for the group.

\section{RESULTS}

\section{Participant characteristics}

One hundred and forty three pregnant women $(79.4 \%$ of the women approached) agreed to participate in the study and 47 $(32.9 \%)$ returned their seven day diary (table 1$)$. The main reason given by women refusing to partake in the study when approached was predominantly time constraint. Participating pregnant women completing the questionnaire were highly educated (65.0\% with university degrees), employed (66.4\%), and had a high household income. They were typically aged $25-34$ years $(58.7 \%)$ and were having their first child $(58.0 \%)$. The women recruited were mostly white in ethnic origin $(74.8 \%)$ and did not smoke $(90.9 \%)$. The demographic and socioeconomic characteristics of participants completing the seven day diary and questionnaire were very similar (table 1).

\section{Cooking and washing up}

On average, women spent almost as much time boiling water as they did using the dishwasher (table 2), although $55.2 \%$ of the participants did not use a dishwasher. Some women used the dishwasher for up to $840 \mathrm{~min} /$ week. On average, women spent $338.5 \mathrm{~min} /$ week cooking and washing up with water, but some women spent up to $1180 \mathrm{~min} /$ week on these activities.

\section{Showering and bathing}

Showering was reported by $76.9 \%$ of the participants and $70.6 \%$ reported bathing. Pregnant women spent almost the same time showering ( $54.3 \mathrm{~min} /$ week $)$ as they did bathing (54.7 $\mathrm{min} /$ week), and $31.5 \%$ and $34.3 \%$ respectively did not spend any time in the bathroom afterwards. Women tended to spend longer in the bathroom after showering than after bathing (table 2).

\section{Swimming}

On average, pregnant women went swimming for $67.9 \mathrm{~min} /$ month (table 2); the maximum time recorded for swimming was $480 \mathrm{~min} /$ month. However, $49.6 \%$ of participants reported to never go swimming or had stopped swimming during pregnancy.

\section{Food and drink}

Pregnant women generally had a higher fluid intake at home ( $11.9 \mathrm{l} /$ week) than work and elsewhere ( $7.0 \mathrm{l} /$ week) (table 3$)$. On average women drank almost equal amounts of cold tap water and bottled water at home, but at work and elsewhere they drank almost three times more bottled water than cold tap water. However, a large proportion of women did not drink cold tap water at home $(42.7 \%)$ and an even greater proportion at work and elsewhere (71.3\%). Overall, $37.1 \%$ of 


\begin{tabular}{|c|c|c|c|c|}
\hline \multirow[b]{2}{*}{ Characteristics } & \multicolumn{2}{|c|}{ Questionnaire } & \multicolumn{2}{|c|}{ Seven day diary } \\
\hline & $\mathrm{n}$ & (\%) & $\mathbf{n}$ & (\%) \\
\hline Participants & 143 & $(100)$ & 47 & $(100)$ \\
\hline \multicolumn{5}{|l|}{ Age group } \\
\hline $18-24$ years & 16 & (11.2) & 4 & (8.5) \\
\hline $25-34$ years & 84 & (58.7) & 32 & (68.1) \\
\hline $35-44$ years & 43 & (30.1) & 11 & (23.4) \\
\hline \multicolumn{5}{|l|}{ Education } \\
\hline None & 2 & (1.4) & 1 & (2.1) \\
\hline GCSE & 15 & (10.5) & 3 & (6.4) \\
\hline A level & 20 & (14.0) & 4 & (8.5) \\
\hline Degree & 93 & (65.0) & 36 & (76.6) \\
\hline Other & 11 & (7.7) & 2 & (4.3) \\
\hline Status not given & 2 & (1.4) & 1 & $(2.1)$ \\
\hline \multicolumn{5}{|l|}{ Employment } \\
\hline Employed & 95 & (66.4) & 31 & (66.0) \\
\hline Unemployed & 47 & (32.9) & 16 & (34.0) \\
\hline Status not given & 1 & (0.7) & 0 & (0) \\
\hline \multicolumn{5}{|l|}{ Previous children } \\
\hline 0 & 83 & $(58.0)$ & 29 & (61.7) \\
\hline 1 & 37 & (25.9) & 12 & (25.5) \\
\hline 2 & 14 & (9.8) & 2 & (4.3) \\
\hline 3 & 3 & (2.1) & 1 & (2.1) \\
\hline 5 & 1 & (0.7) & 1 & (2.1) \\
\hline 6 & 2 & (1.4) & 1 & (2.1) \\
\hline Status not given & 3 & (2.1) & 1 & (2.1) \\
\hline \multicolumn{5}{|l|}{ Household income } \\
\hline Under $£ 10000$ & 13 & (9.1) & 1 & (2.1) \\
\hline$£ 10000-£ 20000$ & 8 & (5.6) & 3 & (6.4) \\
\hline$£ 20000-£ 30000$ & 15 & (10.5) & 3 & (6.4) \\
\hline$£ 30000-£ 50000$ & 19 & (13.3) & 4 & (8.5) \\
\hline$£ 50000-£ 100000$ & 52 & (36.4) & 21 & (44.7) \\
\hline Over $£ 100000$ & 26 & (18.2) & 11 & (23.4) \\
\hline Status not given & 10 & (7.0) & 4 & (8.5) \\
\hline \multicolumn{5}{|l|}{ Smoking } \\
\hline Smoker & 11 & (7.7) & 2 & (4.3) \\
\hline Non-smoker & 130 & (90.9) & 45 & (95.7) \\
\hline Status not given & 2 & (1.4) & 0 & (0) \\
\hline \multicolumn{5}{|l|}{ Ethnic background } \\
\hline White & 107 & (74.8) & 39 & (83.0) \\
\hline Black & 15 & (10.5) & 3 & (6.4) \\
\hline Oriental & 2 & (1.4) & 1 & $(2.1)$ \\
\hline Indian & 5 & (3.5) & 1 & (2.1) \\
\hline Other & 11 & (7.7) & 3 & (6.4) \\
\hline Status not given & 7 & (4.9) & 0 & (0) \\
\hline
\end{tabular}

the study participants did not drink cold tap water and 20.3\% did not drink bottled water.

Hot beverages (tea, coffee, and hot chocolate) were among the most common form of fluid intake-at home on average women drank $2.3 \mathrm{l}$ /week and at work and elsewhere women drank $1.2 \mathrm{l} /$ week. Also, women drank almost the same amount of milk, squash, and soft drinks at home and, to a lesser extent, at work and elsewhere. Overall, $55.9 \%$ of the

Table 2 Summary of data for cooking and washing up patterns (in min/week), showering and bathing patterns (in min/ week), and swimming patterns (in $\mathrm{min} / \mathrm{month}$ ) from the questionnaire

\begin{tabular}{|c|c|c|c|c|c|c|c|c|c|c|}
\hline & \multicolumn{10}{|c|}{ Questionnaire } \\
\hline & \multirow[b]{2}{*}{$\mathbf{n}$} & \multicolumn{2}{|c|}{$\begin{array}{l}\text { Not taking part } \\
\text { in activity }\end{array}$} & \multirow{2}{*}{$\begin{array}{l}\text { Arithmetic } \\
\text { mean }\end{array}$} & \multirow{2}{*}{\multicolumn{2}{|c|}{ Arithmetic SD Median }} & \multicolumn{3}{|c|}{ Percentile distribution } & \multirow[b]{2}{*}{ Max. } \\
\hline & & $\mathbf{n}$ & (\%) & & & & 25 & 75 & 95 & \\
\hline \multicolumn{11}{|c|}{ Cooking and washing up (min/week) } \\
\hline Boiling water & 143 & 8 & $(5.6)$ & 125.9 & 136.8 & 70.8 & 30.4 & 170.6 & 420 & 840 \\
\hline Washing up & 143 & 12 & (8.4) & 89.9 & 96.6 & 70 & 30.4 & 105 & 253.8 & 700 \\
\hline Dishwasher & 143 & 79 & (55.2) & 122.6 & 176.6 & 0 & 0 & 228.8 & 470.6 & 840 \\
\hline Total & 143 & 2 & $(1.4)$ & 338.5 & 259.5 & 279.2 & 128.2 & 490 & 842.2 & 1180 \\
\hline \multicolumn{11}{|l|}{ Personal washing (min/week) } \\
\hline Showering & 143 & 33 & (23.1) & 54.3 & 47.2 & 50 & 14.1 & 73.1 & 148.5 & 210 \\
\hline In bathroom after showering & 143 & 45 & (31.5) & 39.3 & 51.3 & 32.5 & 0 & 70 & 137 & 420 \\
\hline Bathing & 143 & 42 & (29.4) & 54.7 & 65.6 & 30 & 0 & 90 & 176.4 & 420 \\
\hline In bathroom after bathing & 143 & 49 & (34.3) & 23.9 & 44.8 & 10 & 0 & 34.6 & 98.5 & 420 \\
\hline Total & 143 & 0 & (0) & 172.2 & 130.3 & 150.8 & 105 & 204 & 347.8 & 1400 \\
\hline \multicolumn{11}{|l|}{ Swimming (min/month) } \\
\hline Swimming & $141^{*}$ & 70 & $(49.6)$ & 67.9 & 103.2 & 16.7 & 0 & 120 & 330 & 480 \\
\hline
\end{tabular}




\begin{tabular}{|c|c|c|c|c|c|c|c|c|}
\hline \multirow[b]{3}{*}{ Characteristic } & \multicolumn{8}{|c|}{ Questionnaire } \\
\hline & \multirow[b]{2}{*}{$\mathbf{n}$} & $\begin{array}{l}\text { Not } \\
\text { ingested }\end{array}$ & \multirow{2}{*}{$\begin{array}{l}\text { Arithmetic } \\
\text { mean }\end{array}$} & \multirow{2}{*}{$\begin{array}{l}\text { Arithmetic } \\
\text { SD }\end{array}$} & \multirow[b]{2}{*}{ Median } & \multicolumn{2}{|c|}{$\begin{array}{l}\text { Percentile } \\
\text { distribution }\end{array}$} & \multirow[b]{2}{*}{ Max. } \\
\hline & & n (\%) & & & & 257 & $75 \quad 95$ & \\
\hline \multicolumn{9}{|l|}{ Home } \\
\hline Tap water & 143 & $61(42.7)$ & 3.0 & 4.4 & 1.4 & 0 & $4.2 \quad 9.9$ & 36.4 \\
\hline Bottled water & 143 & $60(42.0)$ & 3.1 & 4.1 & 1.4 & 0 & 4.613 .5 & 21 \\
\hline $\begin{array}{l}\text { Hot beverages (tea, coffee, } \\
\text { hot chocolate) }\end{array}$ & 143 & $26(18.2)$ & 2.3 & 3.5 & 1.4 & 0.6 & $3.0 \quad 5.7$ & 37.8 \\
\hline Milk & 143 & $75(52.4)$ & 1.0 & 1.9 & 0 & 0 & $1.4 \quad 3.8$ & 16.8 \\
\hline Squash & 143 & $85(59.4)$ & 1.1 & 2.1 & 0 & 0 & $1.4 \quad 4.2$ & 16.8 \\
\hline Soft drinks & 143 & $76(53.1)$ & 0.8 & 1.3 & 0 & 0 & $1.4 \quad 4.2$ & 5.6 \\
\hline $\begin{array}{l}\text { Alcoholic beverages } \\
\text { (beer, wine, spirit) }\end{array}$ & 143 & $100(69.9)$ & 0.2 & 0.3 & 0 & 0 & $0.2 \quad 0.8$ & 2.8 \\
\hline Soup & 143 & $75(52.4)$ & 0.4 & 0.7 & 0 & 0 & $0.4 \quad 1.4$ & 4.2 \\
\hline Total drinks & 143 & $0(0)$ & 11.9 & 7.9 & 11.3 & 7.41 & 14.822 .1 & 74.6 \\
\hline \multicolumn{9}{|l|}{ Work and elsewhere } \\
\hline Tap water & 143 & $102(71.3)$ & 1.3 & 2.4 & 0 & 0 & 1.47 .0 & 9.8 \\
\hline Bottled water & 143 & $61(42.7)$ & 3.6 & 5.6 & 1.4 & 0 & 6.011 .3 & 38.5 \\
\hline $\begin{array}{l}\text { Hot beverages (tea, coffee, } \\
\text { hot chocolate) }\end{array}$ & 143 & $76(53.1)$ & 0.8 & 0.8 & 0.6 & 0 & $1.2 \quad 2.8$ & 3 \\
\hline Milk & 143 & $135(94.4)$ & 0.1 & 0.3 & 0 & 0 & 0.5 & 2.8 \\
\hline Squash & 143 & $115(80.4)$ & 0.3 & 0.8 & 0 & 0 & $\begin{array}{ll}0 & 2.7\end{array}$ & 4.2 \\
\hline Soft drinks & 143 & $92(64.3)$ & 0.4 & 0.8 & 0 & 0 & $0.5 \quad 2.8$ & 4.2 \\
\hline $\begin{array}{l}\text { Alcoholic beverages } \\
\text { (beer, wine, spirit) }\end{array}$ & 143 & $122(85.3)$ & 0.1 & 0.2 & 0 & 0 & $\begin{array}{ll}0 & 0.4\end{array}$ & 1.4 \\
\hline Soup & 143 & $116(81.1)$ & 0.1 & 0.3 & 0 & 0 & $\begin{array}{ll}0 & 0.8\end{array}$ & 1.4 \\
\hline Total drinks & 143 & $31(21.7)$ & 7.0 & 6.8 & 5.8 & 0.91 & 10.420 .1 & 38.5 \\
\hline \multicolumn{9}{|l|}{ Total } \\
\hline Tap water & 143 & $53(37.1)$ & 4.3 & 3.8 & 2.1 & 0 & $5.8 \quad 12.4$ & 12.8 \\
\hline Bottled water & 143 & $29(20.3)$ & 6.6 & 7.3 & 5.4 & 0.8 & 9.821 .0 & 52.5 \\
\hline $\begin{array}{l}\text { Hot beverages (tea, coffee, } \\
\text { hot chocolate) }\end{array}$ & 143 & $18(12.6)$ & 3.5 & 3.8 & 2.8 & 1.4 & 5.28 .4 & 37.8 \\
\hline Milk & 143 & $74(51.7)$ & 1.1 & 1.9 & 0 & 0 & $1.4 \quad 4.5$ & 16.8 \\
\hline Squash & 143 & 81 (56.6) & 1.4 & 2.5 & 0 & 0 & $2.2 \quad 6.9$ & 16.8 \\
\hline Soft drinks & 143 & $53(37.1)$ & 1.3 & 1.7 & 0.6 & 0 & $1.6 \quad 4.5$ & 9.8 \\
\hline $\begin{array}{l}\text { Alcoholic beverages } \\
\text { (beer, wine, spirit) }\end{array}$ & 143 & $88(61.5)$ & 0.2 & 0.4 & 0 & 0 & $0.4 \quad 1.1$ & 2.8 \\
\hline Soup & 143 & $63(44.1)$ & 0.5 & 0.8 & 0.2 & 0 & $0.6 \quad 1.7$ & 4.2 \\
\hline Total drinks & 143 & $O(0)$ & 18.9 & 9.8 & 17.5 & 13.42 & 23.336 .2 & 81.6 \\
\hline
\end{tabular}

women consumed soup, with this mainly being consumed at home.

On average pregnant women consumed $0.2 \mathrm{l} /$ week of alcoholic beverages (beer, wine, and spirits) at home, but some women reported an alcoholic intake of up to $2.8 \mathrm{l} /$ week. Similarly, on average pregnant women consumed 0.1 l/week of alcoholic beverages at work and elsewhere, but some reported drinking 1.4 l/week. Eighty eight women (61.5\%) did not consume any alcoholic beverages.

\section{Differences by demographic status}

Differences in pregnant women's exposure to tap water through the various activities due to age group, education level, employment status, parity, household income, smoking habits, and ethnic background were also examined (data not shown). Some differences were observed with age group, parity, employment status, income, and smoking habits, but the number of women in the categories was small and there were generally no trends, with a few exceptions. ${ }^{20}$ Boiling water and washing up tended to increase with parity, while the use of dishwasher increased and duration washing up by hand decreased with income. Unemployed women tended to boil more water, wash up more, and showered and/or bathed more often.

\section{Validation}

The results from the questionnaire displayed moderate to good correlation with those from the seven day diary (table 4). Of the cooking and washing up variables, the correlation for dishwasher use $(r=0.82)$ was particularly high. The correlations for the showering and washing variables were also high ( $r=0.76$ to 0.80$)$. Good correlations were observed for drinking cold tap water $(r=0.79)$ and bottled water $(r=0.70)$ at home, but these were only moderate for work and elsewhere (cold tap water, $r=0.43$; bottled water, $r=0.55)$. Absolute differences between the questionnaire and seven day diary revealed some differences in the fluid intake variables (table 4).

Generally, the correlation was better and the differences smaller between the questionnaire and diary results for estimated fluid intake at home compared to elsewhere. Women tended to overestimate their exposure to water in the questionnaire compared to the seven day diary (table 4). Further detail on the subset of diary completers is available in Kaur. ${ }^{20}$

\section{DISCUSSION}

This study successfully obtained exposure estimates for the main activities related to exposure of pregnant women to water in Central London. Examination of the data revealed considerable exposure variability between individuals. Furthermore, fluid ingestion estimates highlighted that most of the fluid intake took place at home $(63 \%)$ and that there are differences in the consumption of cold tap and bottled water in the home and elsewhere. The questionnaire appears to be a valid methodology for estimating the exposure of 
Table 4 Spearman correlation coefficients for the same variables in the questionnaire and seven day diary, and the average differences between the questionnaire and seven day diary $(n=47)$

\begin{tabular}{|c|c|c|c|}
\hline \multirow{2}{*}{$\begin{array}{l}\text { Variables (questionnaire versus seven day diary) } \\
\text { Boiling water (min/week) }\end{array}$} & \multirow{2}{*}{$\begin{array}{c}\begin{array}{c}\text { Spearman } \\
\text { correlation } \\
\text { coefficient }\end{array} \\
0.46^{* *}\end{array}$} & \multicolumn{2}{|c|}{$\begin{array}{l}\text { Average of differences } \\
\text { between the two methods (\%) }\end{array}$} \\
\hline & & 60.81 & (26.01) \\
\hline Washing up ( $\mathrm{min} /$ week) & $0.50^{* *}$ & 23.45 & (16.91) \\
\hline Dishwasher (min/week) & $0.82^{* *}$ & 29.43 & (6.48) \\
\hline Total time (min/week) washing up & $0.68^{* *}$ & 113.68 & (23.57) \\
\hline Showering (min/week) & $0.80^{* *}$ & -12.43 & $(-8.74)$ \\
\hline After showering in bathroom ( $\mathrm{min} /$ week) & $0.80^{* *}$ & 3.45 & $(-1.86)$ \\
\hline Bathing (min/week) & $0.76^{* *}$ & 6.87 & (13.31) \\
\hline After bathing in bathroom ( $\mathrm{min} /$ week) & $0.76^{* *}$ & -1.70 & (10.26) \\
\hline Total time showering, bathing, and in bathroom ( $\mathrm{min} /$ week) & $0.58^{* *}$ & -3.81 & $(1.27)$ \\
\hline Swimming (min/month) & $0.72^{* *}$ & -60.00 & $(-21.49)$ \\
\hline $\begin{array}{l}\text { Overall total exposure from cooking and washing up, personal } \\
\text { washing, and swimming (min/week) }\end{array}$ & $0.76^{* *}$ & 112.03 & (13.49) \\
\hline Tap water (home) (I/week) & $0.79^{* *}$ & 0.62 & (11.67) \\
\hline Tap water (work and elsewhere) (I/week) & $0.43^{* *}$ & 0.87 & $(-0.09)$ \\
\hline Total tap water (I/week) & $0.77^{* *}$ & 1.44 & $(13.05)$ \\
\hline Bottled water (home) (I/week) & $0.70^{* *}$ & 0.66 & (3.23) \\
\hline Bottled water (work and elsewhere) (I/week) & $0.55^{\star *}$ & 0.91 & $(-0.16)$ \\
\hline Total bottled water (I/week) & $0.71^{* *}$ & 1.55 & (5.71) \\
\hline Hot beverages (home) (I/week) & $0.68^{* *}$ & 0.48 & (13.32) \\
\hline Hot beverages (work/elsewhere) (I/week) & $0.66^{*}$ & 0.52 & $(-2.01)$ \\
\hline Total hot beverages (I/week) & $0.77^{* *}$ & 0.99 & (15.32) \\
\hline Milk (home) (I/week) & $0.51^{* *}$ & 0.15 & $(6.83)$ \\
\hline Milk (work and elsewhere) (I/week) & -0.8 & -0.09 & $(-8.51)$ \\
\hline Total milk (I/week) & $0.60^{* *}$ & 0.10 & $(-0.79)$ \\
\hline Squash (home) (I/week) & $0.52^{\star \star}$ & 0.33 & $(-2.08)$ \\
\hline Squash (work and elsewhere) (I/week) & 0.27 & -0.10 & $(-18.35)$ \\
\hline Total squash (I/week) & $0.49^{* *}$ & 0.22 & $(-11.74)$ \\
\hline Soft drinks (home) (I/week) & $0.32^{*}$ & -0.56 & $(-21.70)$ \\
\hline Soft drinks (work and elsewhere) (I/week) & 0.22 & -0.20 & $(-25.79)$ \\
\hline Total soft drinks (I/week) & $0.52^{* *}$ & -0.73 & $(-31.14)$ \\
\hline Alcoholic beverages (home) (I/week) & $0.53^{\star *}$ & 0.08 & (16.31) \\
\hline Alcoholic beverages (work and elsewhere) (I/week) & 0.26 & -0.11 & $(-21.13)$ \\
\hline Total alcoholic beverages (I/week) & $0.69^{* *}$ & -0.03 & $(-2.26)$ \\
\hline Soup (home) (I/week) & $0.38^{* *}$ & 0.02 & $(-17.20)$ \\
\hline Soup (work and elsewhere) (I/week) & $0.30^{*}$ & 0.00 & (5.47) \\
\hline Total soup (I/week) & $0.31^{*}$ & 0.11 & $(10.45)$ \\
\hline Total fluid intake at home (I/week) & $0.46^{* *}$ & 1.80 & (7.67) \\
\hline Total fluid intake at work and elsewhere (I/week) & $0.66^{* *}$ & 1.79 & $(0.04)$ \\
\hline Overall total fluid intake (I/week) & $0.55^{\star *}$ & 3.59 & (8.30) \\
\hline
\end{tabular}

pregnant women to water and had a much higher response rate than the seven day diary.

Examination of the participant characteristics revealed the study sample to be composed principally of educated and affluent white pregnant women aged 25-34 years, reflecting the study area but not generally the rest of the UK. The water exposure of pregnant women seen in this study may differ to that of the general UK population, such as drinking more filtered and bottled water, but there are no national data for comparison. However, there was no trend in the consumption of bottled water by income or education level in the study population, suggesting that these may not be important factors influencing the use of alternatives to tap water. The proportion of women drinking tap water was fairly similar to the rest of the population in London $(69 \%) .{ }^{26}$ The use of a dishwasher increased and time spent washing up by hand decreased with income, but there were no other obvious differences between, for example, different socioeconomic classes and levels of education.

Although the response rate for the diary was low, probably reflecting the respondent burden, the groups completing the questionnaire and the diary had similar characteristics and are likely to be representative of the actual population attending the antenatal clinics. The fairly good correlations and relatively small differences between the questionnaire and diary results suggest that the questionnaire is good enough to collect this kind of information without the women requiring to fill out a diary. Correlations were found to be higher for the "home" variables in contrast to those for "elsewhere". The correlations for cooking and washing up, showering and bathing, and swimming were higher than for the fluid intake variables. This is likely to be due to fluid intake having a greater potential for daily variation in contrast to established routine activities such as cooking and washing up, showering and bathing, and swimming. In comparison to other studies, the correlations in this study were higher than those in a US study, ${ }^{18}$ and some were similar to the correlations found in an Italian study. ${ }^{19}$

Approximately 92\% women reported washing dishes in the current study, which was higher than reported by Zender and colleagues $^{14}(66.2 \%)$. This could be an indication of the difference between the activities and exposure patterns of 
pregnant women in the USA and UK. Unfortunately, no consideration was given to pregnant women washing clothes by hand in this study. This may be particularly important in lower socioeconomic groups who do not have the use of a washing machine, and could be a significant route of exposure, although the number of women is likely to be small.

Pregnant women spent $54.3 \mathrm{~min} /$ week showering and $54.7 \mathrm{~min} /$ week bathing on average. Similarly, $\mathrm{Chu}^{21}$ found women to spend on average $57.4 \mathrm{~min} /$ week showering, but a lot longer bathing ( $129.5 \mathrm{~min} /$ week). Other studies have found the daily duration of showering and bathing to be higher in the USA $^{1418}$ and Italy. ${ }^{19}$ This could be due to a number of reasons, such as differences in cultural characteristics of the pregnant women geographically or simply dissimilarities in climate or even differences in the frequency of showering and bathing. Unlike previous studies, consideration was also given to the time spent in the bathroom after showering or bathing. Women remained in the bathroom for half as much time as they spent showering or bathing, and this may be a potentially important route of inhalation exposure that is often ignored. ${ }^{5}$ However, the current study did not take into account the presence of ventilation within the bathroom and the temperature at which the baths and showers were taken, which have been shown to be important factors for the level of exposure. ${ }^{22-24}$

Half the women participating in this study went swimming. A similar trend was observed by Nieuwenhuijsen and colleagues, ${ }^{17}$ in which $41 \%$ women reported swimming. In two US studies, ${ }^{14}{ }^{18}$ only $25.4 \%$ and $7.5 \%$, respectively, of the study participants reported swimming. Once more, differences in exposure estimates seen between the studies could be potentially due to cultural and geographical characteristics of the sample populations.

The average total fluid intake in Italy ${ }^{19}$ was found to be $2.7 \mathrm{l} /$ day according to the pre-delivery questionnaire in the study, which is the same as the approximate average total fluid intake in this study. However, this was found to be $1.86 \mathrm{l} /$ day by Shimokura and colleagues, ${ }^{18}$ and $3.4 \mathrm{l} /$ day by Zender and colleagues ${ }^{14}$ in the USA. These differences could be attributable to various factors such as sample population diet characteristics and regional climate that can potentially influence fluid intake. This study showed the average total cold tap water intake to be approximately $0.5 \mathrm{l} / \mathrm{day}$, with a higher average intake for total bottled water ( $0.9 \mathrm{l} /$ day). Other studies have similarly found total cold tap water intake to be $0.56 \mathrm{l} /$ day $^{18}$ in the USA and $0.6 \mathrm{l} /$ day $^{19}$ in Italy.

Overall, fluid intake was generally higher in the home environment compared to elsewhere. Sixty three per cent of the total fluid ingestion took place at home, which was similar to the general population in the UK, ${ }^{27} 25 \%$ of this was cold tap water. Shimokura and colleagues ${ }^{18}$ found $66.7 \%$ of the total tap water consumption to occur at home; $48.1 \%$ of this was cold tap water.

As is evident from this comparison of the estimates obtained in the current study and those identified in other studies, the exposure of pregnant women to chlorinated water may differ by geographical locations. ${ }^{18} 19$ Exposure estimates from one country cannot be assumed to be applicable to another country or region. In addition to awareness of geographical variation in water exposure, future exposure assessments for epidemiological studies should consider individual variation, and the potential exposure that occurs outside the home environment.

Exposure assessments in epidemiological studies require a balance or cost benefit analysis ${ }^{25}$ to be resourceful and efficient; studies examining chlorination by-product exposure and adverse birth outcomes with large sample size could have fairly crude exposure assessments (for example, concentrations in water at water zone level), while studies with smaller samples require a more detailed exposure assessment (for example, including information on various exposure pathways and routes).$^{10}$ Particularly for studies with smaller sample sizes, exposure assessment methods need to be refined to ensure they are comprehensive, and that they include the parameters that have been examined in this study.

In epidemiological studies the exposure estimates could be improved by administering the questionnaire twice during pregnancy to obtain better estimates, and to enable the estimation of within and between subject variance and hence the attenuation in risk estimates..$^{10}$ Administration of diaries may be too burdensome and result in low response rates. In addition to comprehensive assessments, methodologies need to be standardised to aid study comparability. Key recommendations for producing better exposure assessments have been reported by Arbuckle and colleagues, ${ }^{13}$ and should be taken into consideration in future designs of exposure assessments. This includes carefully examining consumption characteristics and water use activities for critical exposure periods, factors potentially modifying concentrations (such as water filters, water storage, boiling water, and season), and secondary sources and pathways of exposure (such as pharmaceuticals and occupation).

It is hoped that the detailed assessment of exposure in this study has set a precedent for future examinations of exposure of pregnant women to water. This study has evaluated the use of a questionnaire in a population of pregnant women to assess their exposure to water, and thereby also obtained a better understanding of the exposure of pregnant women to water in Central London. The use of the questionnaire has also been validated with a seven day diary, which has shown it to be a suitable tool to assess exposure.

\section{ACKNOWLEDGEMENTS}

We are grateful to the staff of Chelsea and Westminster Hospital, London, for their assistance, and also to the pregnant women who participated in this study, without whom this project would have not been possible.

\section{Authors' affiliations}

S Kaur, H Ferrier, M J Nieuwenhuiijsen, Imperial College London, Faculty of Life Sciences, Department of Environmental Science \& Technology, South Kensington, London SW7 2AZ, UK

P Steer, Academic Department of Obstetrics \& Gynaecology, Imperial College London, Chelsea \& Westminster Hospital, 369 Fulham Road, London SW10 9NH, UK

\section{REFERENCES}

1 McGeehin MA, Reif JS, Becher JC, et al. Case-control study of bladder cancer and water disinfection methods in Colorado. Am J Epidemiol 1993; 138:492-501.

2 Morris RD, Audet AM, Angelillo IF, et al. Chlorination, chlorination byproducts and cancer: a meta-analysis. Am J Public Health 1992;82:955-63.

3 Hildesheim ME, Cantor KP, Lynch CF, et al. Drinking water source and chlorination by-products: II. Risk of colon and rectal cancers. Epidemiology 1998;9:29-35

4 Graves CG, Matanoski GM, Tardiff RG. Weight of evidence for an association between reproductive and developmental effects and exposure to disinfection by-products: a critical review. Regul Toxicol Pharmacol 2001;34:103-24.

5 Nieuwenhuijsen MJ, Toledano MB, Eaton NE, et al. Chlorination disinfection by-products in water and their association with adverse reproductive outcomes: a review. Occup Environ Med 2000;57:78-85.

6 Savitz DA, Andrews KW, Pastor LM. Drinking water and pregnancy outcome in central North Carolina: source, amount and trihalomethane levels. Environ Health Perspect 1995;103:592-6.

7 Gallagher MD, Nuckols JR, Stallones L, et al. Exposure to trihalomethanes and adverse pregnancy outcomes. Epidemiology 1998;10:484-9.

8 Dodds L, King W, Woolcott C, et al. Trihalomethanes in public water supplies and adverse birth outcomes. Epidemiology 1999;10:233-7.

9 Jaakola JJK, Magnus O, Skondral A, et al. Foetal growth and duration of gestation relative to water chlorination. Occup Environ Med 2001;58:437-42. 
10 Nieuwenhuijsen $M J$, Toledano MB, Elliot $P$. Uptake of chlorination disinfection by-products: a review and a discussion of its implications for exposure assessment in epidemiological studies. J Expo Anal Environ Epidemiol 2000; 10:586-99

11 Reif JS, Hatch MC, Bracken M, et al. Reproductive and developmental effects of disinfection by-products in drinking water. Environ Health Perspect 1996; 104:1056-61

12 Swan SH, Waller K. Disinfection by-products and adverse pregnancy outcomes: what is the agent and how should it be measured? Epidemiology 1998:9:479-81.

13 Arbuckle TE, Hrundey SE, Krasner SW, et al. Assessing exposure in epidemiologic studies to disinfection by-products in drinking water: report from an international workshop. Environ Health Perspect 2002;110(suppl 1):53-60.

14 Zender R, Bachand AM, Reif JS. Exposure to tap water during pregnancy. $J$ Expo Anal Environ Epidemiol 2001;11:224-30.

15 Waller K, Swan SH, DeLorenze G, et al. Trihalomethanes in drinking water and spontaneous abortion. Epidemiology 1998:9:134-40.

16 Klotz JB, Pyrch LA. Neural tube defects and drinking water disinfection byproducts. Epidemiology 1999;10:383-90.

17 Nieuwenhuijisen MJ, Northstone K, Golding J, et al. Swimming and birthweight. Epidemiology 2002;13:725-8.

18 Shimokura GH, Savitz DA, Symanski E. Assessment of water use for estimating exposure to tap water contaminants. Environ Health Perspect 1998; 106:55-9.
19 Barbone F, Valent F, Brussi V, et al. Assessing the exposure of pregnant women to drinking water disinfection byproducts. Epidemiology 2002;13:540-4.

20 Kaur S. Exposure to water in pregnant women and birth weight; a feasibility study. MSc Thesis, Imperial College, University of London, London, 2002.

21 Chu HA. Report to estimate the amount of DBP exposure and the possible health effects to pregnant women who attend indoor swimming pools in London. MSc Thesis, Imperial College, University of London, London, 2000.

22 Kerger BD, Schmidt CE, Paustenback DJ. Assessment of airborne exposure to trihalomethanes from tap water in residential showers and baths. Risk Analysis 2000;20:637-51

23 Weisel CP, Chen WJ. Exposure to chlorination by-products from hot water uses. Risk Analysis 1994;14:101-6.

24 Gordon SM, Wallace L, Callaghan P, et al. Effect of water temperature on dermal exposure to chloroform. Environ Health Perspect 1998; 106:337-45

25 Armstrong BG. Optimising power in allocating resources to exposure assessment in an epidemiologic study. Am J Epidemiol 1996;144:192-7.

26 Drinking Water Inspectorate. Omnibus research 1998. Report no. RS3970. Drinking Water Inspectorate, London, 1998.

27 Hopkins SM, Ellis JC. Drinking water consumption in Great Britain. A survey of drinking water habits and special reference to tap water based beverages. Technical Report no. TR137. Drinking Water Inspectorate, London, 1980.

\section{$\mathrm{ECHO}$}

\section{Air pollution and lung cancer}

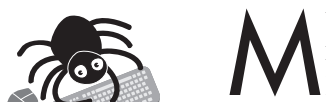

uch has been written about the short term effects of air pollution on health but relatively little about possible long term effects such as lung cancer. Now data from Norway have suggested a link between lung cancer and air pollution.

A population based study of cardiovascular disease included 16209 Oslo men aged 40-49 in 1972-73. Data from this study were linked to data from Norwegian national cancer and

Please visit the Occupational and

Environmental Medicine website [www. occenvmed. com] for a link to the full text of this article. death registries. Data from the Norwegian Institute for Air Research were used to estimate air pollution levels (sulphur dioxide and nitrogen oxides) at the home address of each subject each year for 1974-98. During the period of follow up 2892 men (17.9\%) developed cancer and 422 (2.6\%) developed lung cancer (1.19/1000 men/year). Between 1973 and 1995 estimated sulphur dioxide concentrations tended to fall and estimated nitrogen oxide concentrations tended to rise. After adjusting for age, smoking, and education there was an $8 \%$ increase in lung cancer risk for each $10 \mu \mathrm{g} / \mathrm{m}^{3}$ increase in average home address nitrogen oxide concentration between 1974 and 1978 (risk ratio 1.08, 95\% confidence interval 1.02 to 1.15). For the same increase in sulphur dioxide the corresponding risk ratio was 1.01 (0.94 to 1.08). Average five year (1974-78) exposure to nitrogen oxides at a level of $30 \mu \mathrm{g} / \mathrm{m}^{3} \mathrm{or}$ greater increased the risk of lung cancer by 37\% (crude risk ratio 1.37) compared with an average level of less than $10 \mu \mathrm{g} / \mathrm{m}^{3}$.

Increased home address exposure to nitrogen oxides is associated with increased risk of lung cancer. Compared with smoking urban air pollution is a weak risk factor for lung cancer.

A Thorax 2003;58:1071-1076 